[Published in: Käthe Schneider (ed.), Becoming Oneself: Dimensions of "Bildung" and the facilitation of personality development, Heidelberg/Wiesbaden: Springer VS--Verlag, 2012, pp. 5-28.]

\title{
Becoming Oneself through Failure and Resolution
}

\author{
Jan Bransen, Radboud University Nijmegen
}

\section{Introduction}

The aim of this chapter is to show how we can account for a most peculiar feature of human life: i.e. the need to address the real possibility of failing to be ourselves. I am thinking of situations such as these:

1. In Kazuo Ishiguro's novel The Remains of the Day we witness a butler, Stevens, recalling his days of service under the late Lord Darlington, a German sympathizer, and more especially his never-defined relationship with miss Kenton, the head housekeeper. Stevens remains unable to voice his love for miss Kenton, but he comes to realize that he may have failed to live his own life in professionally and trustingly serving his misguided lord for all those years.

2. Fatima, a young Islamic woman who came to Western Europe as the child of an immigrant, likes to dance and have fun at school parties but also wants to be a good daughter to her traditional father. She is convinced that her problem is not a matter of loyalty to either her friends or her father, but a matter of not knowing how to be true to herself.

3. Martin is an alcoholic - or at least that is what other people say. He knows he drinks a lot, fair enough. But he is in full control - or at least that is what he is convinced of. A friend of his just lost his wife. It is either me or the booze, she had said. Martin knows this much: better get rid of a woman who is forcing your hand. 
4. Charles is a rather humble, quiet man, inclined to listen, mainly, when he is at a party, a reception or a family dinner. He can be quite funny, but he prefers to shy away from center stage. This night, however, he dramatically acts out of character. Making jokes, telling rather personal stories, laughing loudly. He just doesn't seem to be himself.

To be sure, there are many ways to rephrase stories such as these. One may wish to avoid the rather confusing descriptions in terms of persons that fail to be themselves. But in this chapter I shall start from the assumption that phenomenologically speaking we sometimes experience it just like that, as a failure to be ourselves. I shall therefore try to account for such experiences in a way that doesn't imply implausible claims about deeply hidden true essences. The more general claim of this chapter is that we can learn much about the processes of self formation by investigating the possibility of losing and regaining oneself.

This chapter contains six main sections. In section 2 I make some distinctions to specify some of the features of those entities, human beings, of which it makes sense to say that they can fail to be themselves. Section 3 discusses the concept of an alternative of oneself, a concept I claim is needed to account for the phenomenon of failing to be oneself in a way that does not involve a metaphysically problematic story about an original blueprint and a mistaken copy. In section 4 I shall discuss in some detail the experience of reaching deadlock. This, I argue, is a crucial experience to come to a proper appreciation of what it could mean to be true to oneself. Section 5 then explores the conditions of a life that could result in reaching deadlock, after which I discuss, in section 6, how someone facing deadlock might get over it and thereby might improve his way of being himself. This involves, as I discuss in section 7, meeting certain standards indicated by the experience of peace of mind. Becoming oneself in this way, I claim, is not a trivial but a highly significant feature of living one's life.

\section{Being capable of failing to be oneself}

Stones, trees, hutches and flocks, to name but a few items, cannot fail to be themselves. They just are what they are, with no possibility at all for there to be some distance between what they are, essentially, and what they are, existentially. These words from 
Sartre may seem to help, for a start, but as soon as we would focus on essences and existences, and on the related concepts of pour-soi and en-soi it is likely that we easily create more confusion than understanding. Looking at the differences between the ways in which stones, trees, hutches and flocks can merely be themselves might be more instructive.

Stones and trees differ quite dramatically from one another. The issue is not just a matter of a difference between inanimate, or dead, matter on the one hand and living beings on the other hand, although that is obviously significant. But just on a more superficial level stones don't seem to change, or change very, very slowly, requiring external influences and a very long time-scale to make those changes perceptible. Trees, however, change a lot. They do so, not merely as a matter of environmental influences, but also in virtue of their inner dynamics. Trees follow a developmental trajectory. Trees are one of those things Aristotle commented upon when he faced the problem of change and identity and conceived of a solution in terms of the concept of development, entailing the concept of a final cause and the idea of actualizing potentialities. It is this latter idea, the distinction between what a thing is, actually, and what a thing is, potentially, that is helpful in beginning to understand what it might entail to say of something that it fails to be itself. Stones, for instance, are actually just stones, but almost any stone, even though it is actually just a stone, may at the same time be a biface, potentially. Whether or not a specific stone becomes an actual biface is, however, crucially a matter that extends the stone itself and that depends on the attitude and the capacities of a potential biface-user. This seems a remarkable difference between stones and trees. An acorn becomes an oak, whether or not there is a subject to shape the acorn into an oak, or take the resulting tree for an oak. But just how much of a blueprint is present in the acorn and how much causal efficacy, if at all, can be provided for by this blueprint is unclear.

There is an obvious difference, in this respect, between a tree and for instance a hutch, say a rabbit hutch. Every rabbit hutch is constructed, somehow, sometime by someone. Rabbit hutches don't fall out of the sky, just by accident. There must have been a plan, a blueprint of how the hutch would look like if the constructor would succeed in executing this plan. Such a blueprint functions, according to Aristotle, as the constructor's final cause. He undertakes his job, intending to construct the imagined perfect rabbit hutch. But as things often happen, reality doesn't cooperate as nicely as one would have hoped 
for. The actual result is therefore often quite removed from what the hutch potentially could have been. This idea of a blueprint and the companion idea of a less than perfectly cooperative reality gives us a way of thinking about something as not being what it could have been, or even more strongly as not being what it should have been, what it was intended to be.

But, obviously, the materials out of which someone may construct a rabbit hutch have nothing intrinsically to do with the blueprint of the rabbit hutch. The piece of wood, say, that serves in the completed hutch as its left hind leg would not have missed its final destination if it would have ended up being the hutch's right front leg. Pieces of wood don't have a final destination. Things have many potentialities and which one of those becomes actual is most of the time merely a matter of accidental luck. This is definitely the case with construction materials, but it is also, in almost any relevant sense, the case with the potentialities of a tree. Whether it ends up being nine meters high, or with just a few heavy branches facing north, is merely accidental. Of course, trees cannot become giraffes or volcanos, to mention just some very silly potentialities that any tree lacks. But this is not to say that there is just one potentiality that should become actual. There are many, countlessly many ways for a tree to be the tree it is. And there seems to be no point in distinguishing between the many potentialities of a tree, marking a specific subset as more apt for actualisation.

Compare this with the form and direction of a flock of birds. The spectacular phenomenon, for instance, of huge flocks of starlings forming the most magical shapes in the air is well-known, and even though we have something of a story about why starlings flock (safety against predators) and are capable of describing the transformations of a flock with some very simple and basic mathematical formulas, it is obvious that none of all these possible shapes is somehow privileged. Some potentialities may be more likely, or may become more likely given the details of a flock's history, but, as we also know from mathematical models of flocking, the process is unpredictable. A similar kind of story applies to the potentialities of a tree. There are many, and none of them is privileged.

The differences between stones, trees, hutches and flocks gives us the ingredients of a plausible account of what it would be to say of some entity that it failed to be itself. Unlike the stone, such an entity should undergo perceptible changes on a relatively short time-scale. Unlike the flock, such an entity should have a limited number of potentialities 
captured in a blueprint, potentialities that are privileged, that should be actualized over time. Unlike the hutch, the blueprint determining the potentialities to be actualized should be internal to the constituents of the entity. And unlike the tree, an entity that can fail to be itself should be capable of actualizing a potentiality that is wrong, that diverts from the blueprint in a normatively significant way.

Along these lines we can give the beginnings of an account of our human condition as entailing the possibility of failing to be ourselves. We change over time. We actualize potentialities. Some of these potentialities are privileged. Some of them are wrong. I shall argue in this chapter, however, that the image of a blueprint determining which potentialities are privileged and which are wrong is mistaken.

But first I need to say just a bit about what it means for an entity to really have potentialities, alternative possibilities.

A ball can move through a pinball machine in many different ways. There are many possible routes the ball might take, but it doesn't really make sense to say that the ball has many possibilities. Does it make sense to say that there are alternative possibilities for the ball? If we would want to say things like that, it seems we need a subject, capable of imagination. I, for instance, can imagine the many ways the pinball might roll through the playfield, in anticipation. I can look at the machine and imagine how the ball might roll from the moment it is hit by the plunger to the moment it leaves the game. But if there is no relation at all between on the one hand the alternative possibilities I imagine and on the other hand the ball and its movements, it still doesn't make much sense to talk about these possibilities as real possibilities for the ball. We need some link between the anticipated trajectories and the real movements of the ball to make sense of a language in which alternative possibilities are a reality as possibilities. I may, for instance, think about two alternative routes for the ball, one in which I use a flipper to bounce the ball back in the game and one in which I don't touch the flipper button and let the ball leave the game. These two possibilities, it seems, become real possibilities in virtue of two of my capacities: my imagination which allows me to pay attention in anticipation to either of these two possible scenarios; and my capacity to intervene, to choose which of these possibilities will be actualized. Such a choice seems to imply discernment, the capacity to make a qualitative distinction between the two possibilities, privileging one of them as the best option and degrading the other as the 
wrong alternative to be prevented from occuring. So even though there are no real possibilities for the ball, there may be real possibilities for me as a pinball player. This is so in case I can imagine different courses of action I may undertake that will result in the ball either taking this or that route. Imagining these different courses of action also forces me to discern and assess the value of either alternative. Such is part of being capable of acting as a pinball player.

These two capacities - i.e. imagination and discernment - allow me to make sense of scenarios in which there are different courses of action of which I may somehow, by some mistake, choose the wrong one. There is one more capacity needed for an agent to make sense of a story in which he does not merely choose a wrong course of action but in which he fails to be himself. That capacity is reflection, the capacity to imagine and discern alternatives of oneself.

\section{Alternatives of oneself}

I have elsewhere developed the distinction between alternatives for oneself and alternatives of oneself ${ }^{1}$, a distinction that is relevant for the kind of experience I try to account for in this chapter. Linguistically speaking the distinction is simple and straightforwardly enough. Alternatives for oneself are options one can choose from, say pushing or not pushing the flipper button. Such alternatives are available as possible courses of action to agents capable of choosing. In the case of the pinball, these alternatives are alternatives for an agent, say, for me, when I am playing a game on the pinball machine. These alternatives involve alternative routes the pinball may follow through the playfield, but it is obvious that these alternative routes are not alternatives for the pinball. Nothing can be an alternative for a pinball, because a pinball lacks the required capacities: imagination and self-determination. At the same time these different routes are alternatives of the trajectory a pinball may take through the pinball machine's playfield. That's just a matter of the syntax of the prepositions "for" and "of". With respect to the reflexive pronoun "oneself" these different prepositions mark significant features of what may be involved in choosing different courses of action. Look, for instance, at the differences between these two choices:

\footnotetext{
1 Bransen 1996, 2000, 2008.
} 
1. Eating a croissant or eating cereal with yoghurt.

2. Buying a croissant or stealing a croissant.

On a superficial level these choices may look quite similar. Each sentence, one may think, presents two alternatives for oneself, suggesting that the sentences together describe a total of four different alternative courses of action. However, the second sentence does not merely present alternatives for oneself, but also, and by the same token, alternatives of oneself. Why? Because the second sentence presents one with a choice that will have a determinate effect on the kind of person one will turn out to become by making the choice. One can either become an honest citizen who is slightly poorer or a thief who has to run and look out for the police. Of course, something happens too with the person who makes the first choice, between eating a croissant or eating cereal with yoghurt. Choosing the croissant will give you slightly more greasy hands, but such a change is merely temporary, accidental, and external. It does not affect or concern your identity. And that is what the distinction between alternatives for and of oneself is about. A choice between alternatives for oneself is a choice between alternative courses of action that will leave one's identity untouched. But a choice between alternatives of oneself is precisely a choice between two ways of forming or determining one's identity, or in the words used above: a choice between actualizing either this or that potentiality. In my earlier work the main aim of the distinction between alternatives for and of oneself is to point our attention to illuminating reinterpretations of apparently innocent choice situations. Many choices, I argue, have hidden identity-forming effects and focussing on these effects may urge us to reconsider habitual, mindless ways of living our lives. In this chapter my aim is slightly different. My interest here is primarily in questions of identity underlying the concept of an alternative of oneself. In what sense is an alternative of oneself a real potentiality of the person one is? Relatedly and for present purposes more importantly, in what sense can such an alternative of oneself be privileged? What does it mean to say about such alternatives that they are meant to be actualized, or conversely, that they are wrong, mistaken?

The question is not about forms of social or natural aptitude. Stealing a croissant is wrong, morally, and so there are moral reasons why "being a thief" is a potentiality which is not meant to be actualized. But that is not what I am interested in. Nor am I interested in other forms of meeting external norms. If you are a violinist, say, you 
should practice, care for your violin and bow, and wear proper dress if there is a performance of your orchestra. But my question precedes these concerns. My question is about an internal normativity, if that is the right phrase. In this example my question would be: should you become, or have become, a violinist in the first place? Are there alternatives of you that are privileged, meant to be actualized, because of you, of who you are, because of the intrinsic value for you of this alternative of you?

It has been argued that the question is empty; that it is meaningless, confused. ${ }^{2}$ It has been argued that there can be no answers that could qualify as appropriate. I am not inclined yet to accept these arguments nor this conclusion. The question seems to haunt Stevens, the butler in The Remains of the Day. He became a butler, a very good one. Professional all over. But looking back at his life, appreciating -with slight bitterness how good he has been, as a butler, he is confused and wonders whether he should have been a butler in the first place, or, given that he is a butler all over, whether he should have been this particular butler of this particular Lord, neglecting possibilities that may have been more privileged, alternatives of himself that actually have so much more speaking in favour of them rather than the butler he turned out to have become. And the question haunts Fatima, the young Islamic woman. After all, it is not because of other people's expectations that she wants to be faithful to her parents and also wants to have fun at dance parties. It is because of these expectations that she is having a difficult time figuring out how to realize the alternative of herself she considers to be privileged, the one she has most reason to realize. It is not so obvious that she is mistaken about herself.

But neither is it obvious how best to make sense of the question. The problem is, after all, that these alternatives of oneself are identity-forming. The problem is one of bootstrapping. ${ }^{3}$ If I become a violinist, it is by virtue of the choices I make that I come to have the identity of someone who wants to be a violinist. So you can ask me after the fact whether I consider "being a violinist" to be a privileged alternative of me. But then, when I am in fact already a violinist, I most likely, and trivially, will confirm this. If you would, however, have asked me before - if you would find a way to ask my rudimentary, underdetermined self (if that's the plausible phrase here) whether I would consider "being a violinist" to be a privileged alternative of me, it is unclear whether I would have

\footnotetext{
2 Bruckner, 2009.

${ }^{3}$ Schick, 1997, 75-77.
} 
sufficient reason to give an answer at all, and if I do, it seems unclear what weight we should give this answer. ${ }^{4}$

Let me recapitulate and identify the question that should be addressed if we are to make sense of the experience of failing to be oneself. Stevens, the butler, looks back at his life and wonders whether the alternative of himself he actualized over the years is the wrong one. Shouldn't he have lived a different life? The normativity at stake in this question is not a matter of morality, socialization, adaptive survival or any other form of external aptitude. The normativity in question is a matter of authenticity, for lack of a better word. The issue is that given who he is, who he really is, whether there were privileged potentialities, identified, let us say, in a blueprint safeguarded in his "deep self". Is there an alternative that should have been actualized, that was meant to be actualized, such that he really failed to be true to himself by having become this particular butler of this particular lord.

It is this issue of being true to oneself and of failing to be oneself that I want to take seriously. And it is this issue that I want to rescue from popular misconstruals based on an essentialist, Platonic model of "original" and "copy". I used bits of such an essentialist model above by talking about a blueprint and about a "deep self". But an essentialist model faces two very obvious and serious problems.

The first is its fixed, static nature. Human beings unfold over time and develop their identity over time. Any person's identity is seriously contingent, determined as it is by all those identity-forming choices we make over our life span. Accepting this contingency, yet appreciating the normative constraints of our identity is at the heart of my problem. A Platonic model solves the question of contingency in a drastic, far too static and essentialist way, by suggesting that all contingency is really a matter of the way in which the actualized copy is a shadow of the real, i.e. ideal original. In the final analysis, however, such a model is bound to accept a property-less core self, a Cartesian soul, but that is obviously also a reductio ad absurdum of the very idea. ${ }^{5}$

The second problem is the reverse side of the first. The original that is supposed to contain a blueprint of the kind of person one should become, is in principle unknowable. Think about the question of finding out whether or not becoming a violinist would be the right, i.e. the authentic thing to do for your child. How would you be able to know

\footnotetext{
${ }^{4}$ I discuss this problem at length in my 2004.

5 Cf. Cuypers, 2001.
} 
unless by just trying out? But trying out involves tampering with what I have elsewhere analysed as your child's interest-defining desires. ${ }^{6}$ Trying to figure out the contours of the original person your child is meant to become is necessarily an interpretative affair, a matter of hammering out an arbitrary, untested blueprint of your child. We may find out, in due course, whether or not your child will flourish as a violinist, whether being a violinist is her all over. But nothing in this process would justify us in claiming that we finally discovered the original through all these exercises with all these alternative copies of your child. In terms of what there is to know, it is copies all the way down. It is pointless to claim that there is a well-determined though unknowable blueprint behind these copies guiding us to the alternatives that should be privileged. The Platonic model of an original behind the copy is defunct.

In the next section I shall introduce and discuss the idea of a "deadlock scenario", an idea, I shall argue, that allows us to make sense of the justifying normativity implied by our identity while accepting at the same time the contingency of our identity.

\section{The deadlock situation}

Late one night, you find yourself in the kitchen, holding the refrigerator door open and peeking inside, but you have forgotten what it is that you are looking for. Is it a piece of cheese, or some orange juice, or perhaps a bottle of beer that you wanted out of the fridge? Perhaps you wanted to check on the supply of milk and eggs. You are befuddled, and feel foolish — even a bit helpless. You feel sort of frozen, as if in a paralysis, in the middle of an action. ${ }^{7}$

This citation from Jaegwon Kim describes a situation that is fairly commonly known even though it is, fortunately, comparatively rare. It is a quite innocent situation of reaching deadlock and an easy one to solve too. Most of the time you decide to return in vain to the place from where you came, hoping to remember your original reason for visiting the kitchen and for looking in the fridge. Often this works. But my interest in the deadlock situation and in the paradigm of Looking in the Fridge is a matter of the way in which lacking a unified, sincere, accurate and articulate reason-citing description of

\footnotetext{
${ }^{6}$ Bransen, 2004.
}

${ }^{7} \mathrm{Kim}, 1998$. 
what you are doing, makes it impossible for you to complete the action you find yourself in the middle of. Note the different ingredients of the deadlock situation:

1. You find yourself in the middle of an action.

2. You cannot complete this action - you will feel frozen, paralysed, forced to retrace your steps - unless you have an appropriate description at your disposal of what you are doing.

3. Such an appropriate description cites the reason for your action, and is furthermore characterised by being articulate, accurate, sincere, and unified.

Looking in the Fridge is a deadlock situation that merely concerns a choice between alternatives for oneself: cheese, orange juice, beer. But it is relatively easy to imagine how the abstract scheme of such a deadlock situation might be exactly similar in case the paralysis would arise out of a choice between alternatives of oneself. Fatima might experience, even literally, how her voice falters when she is about to ask her father permission to visit a school party. She then finds herself in the middle of an action she cannot complete, because there is no description available to her of her action that would, or even could, cite in an articulate, accurate, sincere and unified way her reason for choosing to be a party girl in the eyes of her father.

In the remainder of this chapter I shall use the deadlock situation as a crucial experience agents need in order to acknowledge two different modes of being. The first mode is that of failing to be themselves. The second is a more significant mode that agents may anticipate by imagining a way of resolving their failure and of becoming themselves again. This more significant mode shows authenticity, again for lack of a better word. It is captured, or so I argue, by the normativity entailed in the four qualities the description of the agent's action should have in order for the agent to be really capable of completing precisely this action. These qualities are:

1. Articulate. There are many actions we can perform just like that, in a habitual, mindless way. There is great deal of automaticity that governs most of our movements, without the need for a well-determined, articulate description of what it is we are doing or why we are doing it. This is so, even with most of our actions in Looking in the Fridge. We hold the door open. We peek inside. We frown. We let our eyes wander through the fridge. We may even move our hand and reach out for... well, for what? That is where we 
need articulateness. In a deadlock situation we lack an articulate identification of the "what" of an action such that the intended action cannot be performed. There is an obvious problem here, a problem that is precisely at the heart of the deadlock situation: how can an action be identified as the intended action without there being an articulate description of it?

2. Accurate. Being truthful is a two-fold accomplishment, comprising accuracy and sincerity. ${ }^{8}$ Accuracy is directed outwards, sincerity is directed inwards. A description of the action I find myself in the middle of is accurate if it truthfully locates me as the agent in an unfolding scenario. I cannot be checking my email when I am looking in the fridge, but I may be checking the milk supply. An accurate description identifies the appropriate affordance my action is the correct response to. ${ }^{9}$ That may be why Fatima is really in a deadlock when she is looking in the eyes of her father: he doesn't afford her the chance to identify herself as a girl who wants to have fun at dance parties.

3. Sincere. People are quite good in adapting themselves to what they conceive of as the obvious, normal, required, "only game in town" kind of action. We are quite good in neglecting an edifying reflective attitude ${ }^{10}$ towards our own deeper motives. It is not difficult to imagine how Fatima will continue to please her father on the one hand and how she will try to get along lightly with her friends at school on the other hand, pleasing them too, slightly feeling uncomfortable about how to squeeze all her promises and obligations into one course of action. The deadlock situation as an experience concerned with alternatives of oneself is crucially a matter of sincerity. It requires a description of an agent in an unfolding scenario that truthfully acknowledges that the agent is aware of herself being this agent and that she affords herself to identify herself as this agent. That is, in matters of sincerity it is not so much the case that the environment constitutes an affordance for the agent to respond appropriately, but rather that the agent's identity constitutes such an affordance. The deadlock situation I am interested in is a situation in which for instance Martin, the alcoholic, really cannot afford himself one more opportunity to get drunk. Think of it in terms of nausea, of really feeling disgusted, abhorrent, repugnant with respect to continuing in this selfdenying way of acting. Think of how Fatima will look at her father, as if looking in the

\footnotetext{
${ }^{8}$ See Williams, 2004.

9 The concept of affordance plays an important role in contemporary ecological psychology. Roughly, an affordance is a clue in the environment that indicates possibilities for action. It was originally introduced by James Gibson, 1977.

10 See below, section 6 .
} 
fridge, simply being unable to complete the insincere action she finds herself in the middle of. That is the deadlock situation I argue is relevant to the experience of failing to be oneself. It is also, as I shall discuss in the next two sections, the fulcrum at which one's resolution can begin to set in, the potential choice point at which one can regain being true to oneself.

4. Unified. A reason-citing description of one's action tends to be singular and coherent. The description, that is. "What are you doing?" "I am looking in the fridge to check the milk supply." Actions don't tend to be that singular or that coherent. We behave in more or less inarticulate ways, often being not quite able to describe, explain or understand what exactly it is that we do. Other people interpret what we are doing, respond to their interpretations of our actions, thereby transforming our actions into joint accomplishments that most of the time fit loosely in ongoing narratives. Fatima's father will endorse some story of what he takes his daughter to be doing, of what he heard her say about what she does at school. And so will her friends at school. And so will she, herself. Between the lines of things said and unsaid Fatima may continue for as long as she can stand it to please her parents and friends, to act as ambivalently as required, to cope with life in ways that are as equivocal and as non-committal as possible. The deadlock situation brings such self-deceiving ambivalence to an end. What needs to be completed, in such a situation, is a singular and coherent action, one individuated by a unified, reason-citing description. Absent such a description, the agent blocks, unable anymore to act.

\section{How to provoke a deadlock situation?}

Arguing against some of my views on authenticity, Donald Bruckner gives us a small story about a banker who considers giving up her life of banking for a life of sheep farming. ${ }^{11}$ As I read the story, I find it to be seriously underdetermined, in that it is not about alternatives of oneself, but merely about some alternatives for oneself, some optional courses of action. Let me explain this by emphasizing the relevance of a deadlock situation for questions of authenticity, for questions of being true to oneself and of failing to be oneself.

\footnotetext{
11 Bruckner, 2009, 357.
} 
Suppose you are, indeed, a banker. And suppose you wonder how your life would look if you were to become a sheep farmer instead. You would have different values, would do many different things, would make different choices for you as well as for your beloved ones. The world would be a different one. You would be someone else. You would be someone else. Well, how are we to imagine that? Would you still be you, while being someone else? Or would we merely be talking about another world containing another person, a person that somehow, somewhere, sometime occupied one and the same "spot" as you in a predecessor world out of which both the actual and this imagined alternative world could have developed? Can you - you - really, literally, be someone else?

I argue that this is not an empty question for those of us who face and resolve a deadlock situation. It may be an empty question for others, people in the middle of lives that unfold in quasi-automatic ways. So, does our banker face a deadlock situation? Suppose our banker in the actual world $\mathrm{W}_{1}$ has a wild imagination and begins to dream about being a sheep farmer. Suppose she imagines another world $\mathrm{W}_{2}$ in which she really is a sheep farmer. However she gets along with this fantasy, she must find some place for $\mathrm{W}_{2}$ in the actual world $W_{1}$. Suppose that every now and then she dreams away, imagining this nonreal, potential world, $\mathrm{W}_{2}$, a world she "visits" in those spare moments. Let us assume that $\mathrm{W}_{2}$ is real enough in those moments, and let us further assume that those spare moments in $\mathrm{W}_{1}$ in which our banker "actually lives" in $\mathrm{W}_{2}$ are enough, from our banker's perspective, for $\mathrm{W}_{2}$ to be a world she inhabits. She doesn't really want to be a sheep farmer, but merely wants to dream away, sometimes, imagining that she is a sheep farmer.

Such a story simply makes sense. We are well-acquainted with many such stories, varying in all kinds of ways and degrees. We imagine ourselves in various ways. Charles, the humble, quiet man from the introduction above, may imagine himself being very much an extravert, bravely flamboyant. He may try to enact this imagined alternative. We often enact portions of such imagined worlds in our real lives. When I play football, I imagine, and enact, being a real football player. Transvestites may often have some kind of a double life, living part of their lives as an ordinary male adult in world $\mathrm{W}_{1}$ and another part of their lives as an irresistable, stunning female in an imagined, fictitious quasi-world $\mathrm{W}_{2}$. On the whole such a double life may be a balanced, unified life, albeit probably not the most easy kind of life to live. Yet most of us will have slightly similar 
problems. There will often be some corners in our lives that rebel a bit against the main, overarching narrative. We may, for instance, regret our ineradicable indulgence when our neighbours transgress what we feel are private boundaries, or, on the positive side, forget about our timidity when playing music on stage. Such diverting bits may cause difficulties, may cause little cracks in our narratives, but most of the time they will merely remain inconveniences we can quite well live with. And so may our banker with her fantasy of being a sheep farmer.

But things may become more drastic, up to the point of reaching deadlock. If so, this will be highly significant for one's identity. The banker's fantasy of being a sheep farmer may get a firm hold on her. Should such a drastic experience of sincerely being captivated by an imagined alternative of oneself occur, then it should be based on many significant clues concealed in one's narrative over the years. Think about Martin, the alcoholic. We may give him many credits in believing that he is a willing addict, as he reports. He may be happy with exactly the way his life unfolds. He may be a loner, more comfortable without a girl friend. It just may be. But there will be another story of his life too, if only in the remembered hopes and wishes of his mother who cannot believe he is born to be a drunk. We may take pains to trigger Martin's sensitivity for this other story. We may be his friends, his parents, his children. We may hope to drive Martin to the experience of serious, abhorrent nausea. We may hope to push him towards his deadlock situation, a situation he wouldn't be able to leave without resolving the fate of his life. He is an alcoholic, sure, but not merely. He may be an unwilling addict. He may reach deadlock, unable to get drunk once more, unable, that is, to complete his action because he lacks a unified, sincere, accurate and articulate reason-citing description of what he would be doing finishing his drink.

The same kind of deadlock may overcome the banker, but only if in the end she is really unable to merely put away her desire to be a sheep farmer in the spare moments of the life she lives as a banker. Reaching deadlock, to be sure, is not the same as becoming aware of the fact that one actually is somebody else. When the banker reaches deadlock this does not mean she finally comes to believe that she is "really" a sheep farmer. The deadlock situation offers an alternative to the Platonic model of original and copy. When the banker reaches deadlock it is not as if she finally discovers the blueprint hidden deep inside her and realizes that her being a banker is an actualization of a mistaken copy. But what she does discover is that there is no opportunity any more to carry on with her 
life in an inarticulate way, in a way that fails to address the crucial questions of sincerity, accuracy, and identity.

Reaching deadlock doesn't come cheap. It is not easy to sincerely and accurately confront oneself with the idea that a "look in the fridge" is really as articulate as needed to acknowledge that the flow of one's life came to a halt. Full stop. Human beings cannot just make this up. People cannot create just like that an impasse at the center stage of their lives unless the world - the actual world $\mathrm{W}_{1}$ - cooperates. The banker will not reach deadlock, unless there are real sheep farmer values at stake that are incommensurable with her banker values and that somehow played an unclear, concealed role in the life she lived so far. It is this single life that she were able to live so far, but that now uncovers itself, in the deadlock situation, as being burdened by an unbearable conflict between being a banker and being a sheep farmer. The deadlock situation is seriously captivating. The story of Fatima may offer the most striking illustration. We can imagine her, speaking to her father, trying to explain to him that she values him as her father, that she respects him as a sincere, devout, good parent, but that at the same time she really wants to... ehh... wants to.... It is in such an internal interruption, being unable to say what it seems she was about to say, that she reaches deadlock. ${ }^{12}$ Just like in Looking in the Fridge there are, of course, many easy and superficial ways to get out of the deadlock and to ignore the real issue. The deadlock captivates Fatima. She is unable to complete the action she finds herself in the middle of. But she may retrace her steps, as we would do in Looking in the Fridge. Fatima may refuse to address the question of incompatible alternatives of herself. She may refuse to address the question of her identity, of looking for an articulate, accurate, sincere, and unified reason-citing description of what she needs to tell her dad. And so may Martin, the alcoholic. But both Martin and Fatima know, or should be able to be sensitive enough to acknowledge, that the question of identity is haunting them. This is probably not the case with the banker as she is depicted in Bruckner's argument. This banker is merely choosing between alternatives for herself. But in a different world another banker may be forced to acknowledge that she reached deadlock.

\footnotetext{
12 There are attempts in psychological research to study these processes empirically. See, for instance, Hermans, 1996.
} 


\section{Regaining flow}

It is in managing such a deadlock situation that people will be able to spot a glimpse of what it means to fail to be oneself and what it would mean to be true to oneself in a more mature, more edified way. Such a glimpse is not a glimpse of the original in the Platonic model; but it is an instance of sensing 'authentic quality', if that is the right word. Such a glimpse, I argue, happens when we regain the flow of our lives, using, firstly, our imagination in discerning viable alternatives of ourselves, and, secondly, our edifying reflection to determine which of these is the best alternative. Trying to regain the flow of our lives involves a process of dramatic rehearsal, of an imaginary mental dry run. ${ }^{13}$ It requires that we imaginatively organize an inner conversation between the alternatives of ourselves. In a series of turns we should take the perspective of each of the contingent, viable alternatives of ourselves that play their part in the deadlock situation we are in. We should try to arrange empathic access to what we will feel if we would be either one. There is no guarantee that we will regain the flow of our lives, but if we will, it will, I argue, be a matter of enjoying peace of mind in acting on the articulate, sincere, accurate and unified reason-citing description of our own behaviour. Let me elaborate a bit on the successive steps in this process.

\section{Entering the world of real possibilities. In a deadlock situation we experience our} ordinary course of action, our habitual, quasi-automatic behaviour, as a possibility, a real possibility. Mindlessly living our lives, we may have thought that our actions are not optional at all, that what we find ourselves doing is somehow bound to happen. But reaching deadlock, strikingly enough in the experience of being unable to act, we acknowledge that the action we find ourselves in the middle of and cannot complete is not bound to happen. An even stronger realization is that it cannot happen. We are simply unable to do what we once were capable of doing without any further thought. But this paralysis, this full stop, does not confront us with the absence of free will. Quite the contrary. In a deadlock situation we experience the need, and the capacity, to be the "arbiters" of our own lives, to choose who we will become, to perform a self-forming action. ${ }^{14}$ What we experience in the deadlock situation is that we would be capable of acting if only we would have an articulate, sincere, accurate and unified reason-citing

\footnotetext{
13 The phrase "dramatic rehearsal" is coined by Dewey, 1922.

${ }^{14}$ Kane, 1999.
} 
description of our action at our disposal. It is this need for an appropriate reason-citing description that we will have to take seriously, once we reach deadlock. Take Looking in the Fridge. Our imagination is quick enough: "Is it a piece of cheese, or some orange juice, or perhaps a bottle of beer that you wanted out of the fridge? Perhaps you wanted to check on the supply of milk and eggs." No action is simply available yet, but we discern many possibilities. We are quickly alert, attentive to clues, tracking down our memory that forsakes us. The standard option is of course a possibility too: give in and retrace your steps back to your study, hoping that your reason for looking in the fridge will spring back to mind.

2. Discerning alternatives of oneself. In the examples in the introduction above, concerning Stevens, Fatima, Martin and Charles, our imagination will not be as quick as in such ordinary cases as Looking in the Fridge. Alternatives of oneself don't flock around in large numbers. Ishiguro needs an entire novel to give Stevens, the butler, a few glimpses of a real alternative of himself. And even then Stevens is not really capable of experiencing the deadlock and of imagining that another life, a life with Miss Kenton, could have been a real possibility for him, a real alternative of him. Fatima, however, is really facing deadlock. She really needs to resolve her ambivalence. It would be good for her, I suggest, to imagine her situation as a real either/or. That would require her to imagine herself being a good, faithful daughter of her traditional Islamic father. Full stop. And it would require her to imagine herself being a modern, Westernized, young, Islamic woman. Full stop.

My suggestion is that Fatima can only address the question of her identity by imagining herself to be merely one alternative of herself. She could try out other alternatives in turns in a mental dry run. She should imagine a number of alternatives, each being a wholeheartedly unified continuation of what so far appeared to be merely a part of herself. And she should imagine how an inner conversation between these alternatives would develop. She obviously needs a serious amount of sophisticated and careful imagination for this. For reasons of clear exposition let me focus here merely on Fatima and merely on one of her alternatives: the alternative of her being a faithful daughter of a traditional Islamic father. In order for this alternative to be a continuation of Fatima's life that is true to herself, beyond the deadlock situation, this alternative should include a sincere and accurate story about her, Fatima's, desire to have fun at school parties. This story will probably involve some agent-regret, albeit agent-regret that now has 
found its place in the alternative's overarching and comprehensive motivational profile. There is a desire Fatima once had, a desire that once made her tick. It is a desire she did not act on, which initially seemed a pity, but not anymore, since now she happily and wholeheartedly is a faithful daughter of a traditional Islamic father.

My suggestion is that Fatima imagines what it would be like to be wholehearted in this sense. That is, in terms used above, Fatima needs her imagination to provide a unified, sincere, accurate and articulate reason-citing description of what her life would be like for her, Fatima, the woman who is facing deadlock, if she would be a faithful daughter of a traditional Islamic father. Three comments are in place her. One: there is no guarantee for success. Fatima might be unable to come up with such a description of things to do as a faithful daughter. And there is no guarantee that she will be able to come up with such a description of any of her other alternatives. The deadlock may remain an insurmountable obstacle, as it might, sometimes, in Looking in the Fridge. Sometimes you retrace your steps never to remember again what it was you were looking for. Two: the reason-citing description should not be a description of an alternative for her. The point is not that Fatima should try to conceive of $a$ way in which some faithful daughter of a traditional Islamic father would think about school parties. A generalised story doesn't work. Fatima needs to imagine herself being such a daughter. ${ }^{15}$ The reason to be cited by the appropriate description, that is, should be a reason of her own, a reason grounded in an alternative of herself, an alternative that is a proper continuation of the person Fatima is. ${ }^{16}$ Three: the point of discerning imagined wholehearted-yet-partial continuations of the person one is, alternatives of oneself, is not meant to favour some kind of alienating strategy ${ }^{17}$, but is rather precisely meant to force the agent to really address the inner conflict as an issue the resolution of which the agent should take responsibility for. In this way, I suggest, dramatic rehearsal becomes fruitful.

3. Determining the best alternative of oneself. The verb "to determine" is ambiguous in an important way. It includes both a contemplative sense, as if it involves a discovery, and a constructive sense, as if it involves an active, decisive identification. ${ }^{18}$ Determining

\footnotetext{
15 I analyse this in my 2008 in terms of a person's need to have "empathic access" to the "notional subject" of imagined experiences.

16 I developed an account of a person's "reason of her own" using the concept of an alternative of oneself in my 2004.

17 Frankfurt's work on wholeheartedness is sometimes interpreted along these lines. See, e.g., Poltera, 2010.

18 I analysed this ambiguity in my 1996 and my 2008.
} 
which of a couple of alternatives of oneself is the best has both components: it is both a matter of 'finding' this alternative to be the best and of 'making' it the best. This requires what I shall call "edifying reflection". It begins in dramatic rehearsal, imaginatively taking in turns the perspective of each alternative, trying to answer all the questions the other alternative(s) will direct at each imagined, unified, wholehearted-yet-partial possible self. Such an internal dialogue is quite common, but the idea of dramatic rehearsal is to really position oneself in turns in either one of these inner voices, imagining oneself to be unified, sincere, accurate and articulate in citing one's reasons for what one would do if one would really and wholeheartedly be this alternative of oneself. Imaginatively taking a position, I suggest, activates affective response patterns. ${ }^{19}$ When Fatima tells herself in imagination that she loves to be the daugther her father hopes she is and that she doesn't regret anymore that she never dances at school parties, what she experiences will feel some way, will emotionally be highly significant.

Paying serious attention to one's own affective response patterns requires reflection. And this reflection, I argue, will have an edifying character. The inner conversation, switching positions, voicing appropriate reasons that are available from specific, partial points of view will enable one to grow, psychologically. As I said above, there are no guarantees. Dramatic rehearsal is as contingent and as empirical as any ordinary experiment. And describing the steps here is not much more than a conceptually balanced account of how to execute edifying reflection. Reflectively paying attention to one's own affective responses to one's own attempts to voice a unified, sincere, accurate and articulate reason-citing description of the thing to do, is edifying in that it leads to the determination of the best alternative of oneself. This process will lead one to a more mature, more comprehensive acknowledgement and appreciation of one's own identity.

\section{Peace of mind.}

We have come a long way. To get an idea of what it could mean to fail to be oneself I started in section 2 with making some distinctions between stones, trees, hutches, flocks and human beings. The stones may reappear here as examples of things that dramatically lack perturbation, things that are so quiet and peaceful. What could be

\footnotetext{
${ }^{19}$ In a fascinating paper Tamar Gendler introduces the concept of "alief" to account for the specific type of mental state that produces these affective response patterns. Gendler, 2008.
} 
more deeply quiescent than a stone? Yet, it is obvious that the immobile silence of a stone can only metaphorically be a model for peace of mind. But the absence of perturbation quite nicely captures what I am thinking of in using "peace of mind" as an indication of having determined the best alternative of oneself. ${ }^{20}$ Peace of mind, as I use it, is a sign that one's actual, contingent self-understanding meets certain standards. These are standards that indicate on different levels that one's actual, contingent mode of being is privileged, is a potentiality meant to be actualised. These standards specify intersubjectively and realistically grounded normative constraints of authenticity. Let me explain what I have in mind by using the example of Looking in the Fridge.

a. Intelligibility. Citing reasons for action is part of our narrative practices. In explaining my behaviour I take care to come up with a story that makes sense. Those present to respond to my reason will minimally expect my behaviour and the accompanying reason-citing description to be intelligible. When I look in the fridge, fail to remember what it is I am looking for, I am unable to complete the action I find myself in the middle of. Just in this situation I may, of course, complete many nearby actions, actions that begin in the same way. I may, for instance, look in the fridge, release my watch from my wrist, put it in the fridge and close the door. Just as it stands, this doesn't make sense. An action like this obviously violates implicit intersubjective and realistic normative constraints that govern narrative patterns of intelligibility. My action may make sense, but unless I add an intelligible reason, anyone present will undoubtedly have a perturbed mind.

I could also have done something else, of course, something other people wouldn't recognize as odd. I could have opened the door, look inside, acknowledge that I have not the faintest idea what I am looking for, grab just an arbitrary item, say a bottle of beer, and close the door. My son may be around and he may see me take a beer. It wouldn't disturb him, say, for I regularly take a beer while working. But I myself will have a perturbed mind. For me it wouldn't be intelligible why I would just grab an arbitrary item when I don't remember what it is I am looking for. That doesn't make sense. The implicit intersubjective and realistic normative constraints that govern our ordinary narrative patterns of intelligibility do not merely serve to give other people expectations

\footnotetext{
20 I borrow with approval the term "perturbation" from Maturana \& Varela who use it in their 1987 book to describe the effects of external influences on the internal states of dynamic systems.
} 
about my behaviour. They give me such expectations too. They constrain my selfunderstanding. Just taking out a bottle of beer does surprise me. I need some story here to keep in touch with my own behaviour.

And precisely because I am the agent in the story, my need goes deeper. The story I tell about my behaviour does not merely need to make sense, it does not merely need to possess an internal intelligibility, but it should intelligibly hook on to the larger story of my life as it unfolds in local scenarios such as Looking in the Fridge. That is why a mere arbitrary exercise of impression management is not enough for the agent himself in such a situation. Agents do not merely observe their lives. They live their lives; they want to spin a coherent, ongoing story. That is why I will ordinarily retrace my steps when I forget what it is I am looking for in the fridge. I want to connect, that is, in a meaningful way my actual behaviour to my memories and my intentions.

The best alternative of oneself will definitely be intelligible. It will silence all questions about how to continue one's life, not merely questions of intelligibility, but also, as we shall see, questions of rationality and goodness. The best alternative of oneself is the one that makes one's life regain its flow.

b. Rationality. Not all stories that make sense are rational. Rationality is a stronger normative constraint. It requires that what we do fits in a plan, a plan settled around our beliefs and desires, a plan in which our action fits for instrumental reasons. Suppose you saw me put my watch in the fridge and ask me why. Suppose I tell you there is an invisibly small yeti that lives in my watch. I further tell you that I hate this little creature. And because he loves the cold I put him in the fridge. You will no doubt respond by saying this doesn't make sense, because it is irrational in its own terms. If I really hate that yeti and know he loves the cold I may settle on a number of plans, but in none of those plans my putting my watch in the fridge would fit instrumentally. It would help the yeti, rather than harm him.

Okay, I reply, I just wanted to check whether you were really paying attention to my words. In fact, I continue, I very much care for this small yeti, and since he complained that it is so hot, I decided to give him a chance to cool down in the fridge. I guess you will reply by admitting that this second story is better because it is rational, internally, which is to say coherent. But, you will add, it will definitely be irrational on external grounds. Believing that an invisibly small yeti lives in my watch is so lunatic. Rational people would test their beliefs, you will say, discarding those that fail to be true. And it may just 
be true, but it sounds so terribly implausible, to say the least. Yeti's don't exist. And if they would, they would be huge, not small. And even if they would be small, it is difficult to believe they would be invisibly small. How small would that be? And even if there would be such a small yeti, why on earth would it live in a watch?

Suppose I admit that the second story isn't true either. Actually, I say, I forgot what it was I was looking for in the fridge. This really annoyed me, but to be honest I'm also fed up with the way you are always keeping an eye on me. And then it suddenly occurred to me that I could release my frustration about myself by luring you with a bizarre story about a yeti in my watch, making you feel silly rather than me. This third story seems to meet a comprehensible standard of instrumental rationality. It explains a plan, grounded in my beliefs and desires, and my actions fit in this plan, instrumentally, as steps in its execution. Whether or not this really was my plan and whether or not this is a good plan to settle on are questions that may be too difficult for you to answer. Perhaps they don't bother you, but as the agent framed in Looking in the Fridge these questions should bother me. Why would I engage in this silly attempt to ridicule my friend when, actually, I do not know what it is I am looking for in the fridge? What does this tell about me? Living my life, in local scenarios such as Looking in the Fridge, but also on the larger scale of my life span, will make me sensitive to instrumental rationality as a standard to meet. It invites and requires me to think of stretches of my life as coherent plans to settle on. This standard will definitely play a role in determining the best alternative of myself. Peace of mind is hard to come by when you settle on a frustrating plan, a plan that doesn't fit your circumstances, your competences, your opportunities. Charles, the humble man from the introduction above who loudly acts out of character, may be experimenting with new behaviour. He may set up small plans (does he follow up a therapist's advice?), trying out behaviour he hopes will fit him. These plans will fit in a larger plan, and the point of this discussion of rationality as a relevant standard is that determining the best alternative of oneself will involve an attempt to settle on a plan that gives a person the best prospect for peace of mind. Charles may be very annoyed by his own shyness. He may feel alienated, sincerely, from his own unsociable behaviour. It may make him feel very uncomfortable. And so he tries to enact a more extravert version of himself. It may work. He may catch up. Other stories are possible too, of course, about Charles. Was he drunk, for once? Does he try to be someone he is not, someone he thinks others hope he can be? Instrumental rationality is one of the 
standards here. It is not a cold standard. It is not overly intellectual. It is about behaviour that fits a life. It is about emotions, about our affective response patterns. It is about the peace of mind that will follow in the wake of a good plan to settle on.

c. Goodness. Not all rational plans are good plans. Not all rational plans add up to a good life. There is a third standard: goodness. Goodness is best understood, I should like to argue, along broadly virtue ethical lines. ${ }^{21}$ Take Looking in the Fridge again. I peek inside without a clue of what it is I am looking for. How long will I look? How swift will I let my eyes glide over what is in the fridge? When will I decide it is best to retrace my steps? How attentively should I try to remember what brought me there in the first place? We can try to think of these questions as having an answer that merely needs to meet a standard of rationality. That is, I could try to calculate on the one hand the costs of continuing to look in the fridge hoping to find a clue and on the other hand the costs of returning to the study to remember my reason. It may be possible to compare these costs in terms of their instrumental value to my overall plan that night. There may be psychological mechanisms in play and there may be a general way of calculating a break even point. It may be irrational, from such a rational choice theoretic point of view, to return to my study too early or to hang on in the kitchen for too long.

But it is quite likely, especially in such trivial cases as Looking in the Fridge, that we do not care that much about rationality. Rationality, that is, is just one of our standards. It is a fairly universal one, just like intelligibility, but these two are not the only values to govern our lives. ${ }^{22}$ An obvious third standard is morality. Social choice theory couples the standards of rationality with explicit ethical constraints. Trying to make you feel silly by telling a story about the small yeti in my watch may free me from feeling a fool myself because I forgot what it is I am looking for. But even though trading our feelings in this way may be profitable for me, morality may stop me and may encourage me to choose a more pro-social course of action. If I am the fool here, I shouldn't try to distract the attention from me by making you look silly.

Peace of mind functions as an indicator of this general goodness in dramatic rehearsal. Each alternative of oneself will take turns voicing its reasons for doing what it does in an articulate, sincere, accurate and unified way. Each alternative will raise and address

\footnotetext{
21 See Foot, 2003, for a wonderful account.

22 There is a lot of serious debate about whether or not rationality and goodness are intimately related, up to the point of claiming that in the final analysis they are the same. See for an accessible, slightly partial exposition Blackburn, 2001, 108-135.
} 
questions, concerns and expectations. Each alternative will cite culturally available resources. Each alternative will confront the others with the demands of intelligibility, rationality and goodness. Peace of mind will result when this inner conversation comes to an end, when one of the alternatives succeeds in silencing the others, or when the conversation leads to a novel potentiality, by discerning a more comprehensive, better alternative of oneself than the ones voicing their reasons. Peace of mind, that is, will result when this inner conversation passes into a life that regained its flow: the life of the best alternative of itself.

\section{Conclusion}

In this chapter I have explored the phenomenon of failing to be onself and the related phenomenon of succeeding in being true to oneself. I have explored this phenomenon not merely because it seems to be a highly significant feature of human life, but also because it allowed me to develop an account of some of the main characteristics of the process of human self formation. I have emphasized that the experience of a deadlock situation is crucial to becoming oneself on a deeper level. I have shown how we can try to provoke a deadlock situation, but only if we live in a world that cooperates, a world that really fuels our being captivated by an impasse because in this world we have failed, so far, to be ourselves. And I have shown how we can try to overcome a deadlock situation, by regaining flow. This, I have argued, is a matter of a dramatic rehearsal of an inner conversation between a number of alternatives of oneself that try to provide an articulate, sincere, accurate and unified reason-citing description of the best thing to do. If we succeed in producing such a description, peace of mind - happy reconciliation with ourselves - will be our part. ${ }^{23}$

\footnotetext{
${ }^{23}$ I should like to thank Marc Lewis and Wim de Muijnck for their useful comments on an earlier draft of this paper.
} 
References

Blackburn, Simon (2001), Being Good, Oxford: Oxford University Press.

Bransen, Jan (1996), Identification and the Idea of an Alternative of Oneself. European Journal of Philosophy, 4(1), pp.1-16.

Bransen, Jan (2000), Alternatives of Oneself. Recasting Some of Our Practical Problems. Philosophy and Phenomenological Research, 60(2), pp.381-400.

Bransen, Jan (2004), Anticipating reasons of one's own. In: Sie, M., Slors, M., \& Brink, B. van den (Eds.). Reasons of one's own, pp. 87-105. Hampshire: Ashgate Punblishing Limited.

Bransen, Jan (2006). Selfless Self-Love, Ethical Theory and Moral Practice, 9 (1), pp. 325.

Bransen, Jan (2008), Personal Identity Management. In: C. Mackenzie \& K. Atkins (Eds.), Practical Identity and Narrative Agency, pp 101-120. New York: Routledge.

Bruckner, Donald W. (2009), Silent prudence, Philosophical Explorations, 12(3), pp. 349364.

Cuypers, Stefaan E. (2001), Self-Identity and Personal Autonomy: An Analytical Anthropology, Aldershot: Ashgate Publishing Limited.

Dewey, John (1922), Human Nature and Conduct. In: The Middle Works, 1899-1924, J. A. Boydston (ed.), Carbondale: Southern Illinois University Press.

Foot, Philippa (2003), Natural Goodness, Oxford: Oxford University Press.

Gendler, Tamar S. (2008), Alief and Belief, The Journal of Philosophy, 105, 634-663.

Gibson, James J. (1977), The Theory of Affordances. In: R. Shaw \& J. Bransford (Eds.), Perceiving, Acting, and Knowing, Hilsdale, NJ: Lawrence Erlbaum Associates.

Hermans, Hubert J.M. (1996), Voicing the Self: From Information Processing to Dialogical Interchange, Psychological Bulletin, 119(1), pp. 31-50.

Kane, Robert (1999), Responsibility, Luck, and Chance: Reflections on Free Will and Indeterminism, The Journal of Philosophy, 96(5), pp. 217-240.

Kim, Jaegwon (1998), Reasons and the First Person, In: J. Bransen \& S.E. Cuypers (Eds.), Human Action, Deliberation, and Causation, pp. 67-87.

Maturana, H. R. \& Varela, F. J. (1987). The tree of knowledge: The biological roots of human understanding. Boston: Shambhala Publications 
Poltera, Jacqui (2010), Is Ambivalence an Agential Vice?, Philosophical Explorations, 13(3), pp. 293-305.

Schick, Frederic (1997), Making Choices. A Recasting of Decision Theory, Cambridge: Cambridge University Press.

Williams, Bernard (2004), Truth and Truthfulness, Princeton: Princeton University Press. 